Original Research Paper

\title{
A Didactic Laboratory of Theory and Design of Structures for Bachelor Civil Engineering Students in Cagliari
}

\author{
${ }^{1}$ Mariangela Deligia, ${ }^{2}$ Fabrizio Pittau, ${ }^{3}$ Silvia Corda, ${ }^{4}$ Michele Serra and ${ }^{1}$ Mauro Sassu \\ ${ }^{I}$ Department of Civil Environmental Engineering and Architecture, University of Cagliari, Italy \\ ${ }^{2}$ Private Civil Engineer, Selargius (CA), Italy \\ ${ }^{3}$ Sardinian Green Houses Srl, Sarroch (CA), Italy \\ ${ }^{4}$ Secured Solutions Srl, Spin Off - University of Cagliari, Italy
}

Article history

Received: 31-01-2018

Revised: 06-02-2018

Accepted:7-03-2018

Corresponding Author:

Mauro Sassu

Department of Civil

Environmental Engineering and

Architecture, University of

Cagliari, Italy

Email:msassu@unica.it

\begin{abstract}
The course of Theory and Design of Structures for the Bachelor courses of Civil Engineering in Academic Year 2016-17 at the University of Cagliari was divided in two semesters: the first one dealing with theoretical aspects, in the second one a didactic laboratory was developed with the aim of a structural design of a building. The assignment and development of a series of individual themes of structural design was managed in a classroom of about 120 students. The strategy to optimize the efficiency was to assign a series of simple plane framed structures with comparable difficulty. They were generated from a common building with six identical frames, each composed by four columns and three floors. The removal of beams or columns, together with variations of length, height, location and destination, generated the requested individual themes. The students were then divided into four groups, followed by tutors. They experienced the development of the project in classroom, in a series of twelve sessions: Eight of them were dedicated to develop a prescribed step of the project, two for the inspection activities and the remaining two for harmonizing the project's state of progress of the project. The main educational results are here illustrated.
\end{abstract}

Keywords: Teaching Engineering, Didactic Laboratory, Civil Engineering Students

\section{Introduction}

The structural design of a building is a complex activity, which involves the implementation of concepts acquired during the academic courses, such as Continuum Mechanics, Technical Architecture, Physics, Mathematics, Materials Technology. Approaching for the first time to the development of a structural design requires imagination and creative vision that can not be reduced to the simple application of formulas and design tables. Stimulating the enthusiasm to independently create a small technical project, using and valuing the concept previously learned, results in the enhancing of creativity and curiosity.

The importance of a new educational method where the student actively participates to the activities proposed by the teacher, is widely discussed by many authors. The importance of implementing creativity education in the classroom is extensively debated as well. Indeed, Cropley and Cropley (1991) and Liu and Schonwetter (2004) underlined that teaching creativity has not been fully performed and that facilitating creativity in the engineering students still remains a critical issue for universities. In fact, more opportunities should be provided in order to foster and nurture creativity in engineering students and completing in this way their intellectual development. Shaw (2001) stated that recognizing, validating and solving problems, individually or through team work represent the principal required activities for the profession of engineering. Thus original and critical thinking as well as creativeness and innovativeness are precious characteristics for engineers. According to Martin (1991), engineers need a creative mind to meet the advancing goal of the engineering profession to design new products or systems and improve existing ones for the benefit of the collectivity. 
Rugarcia et al. (2000) stated that significant changes in engineering education will be required if we want to meet the needs of our graduates in preparing them for the challenges of the coming century. Also Breschi and Sassu (1997) and $\mathrm{Wu}$ et al. (2016) illustrated a fullimmersion approach.

This article reports on the organization of a design laboratory for students in the 3rd year of the BsC in Civil Engineering. Students performed for the first time a structural design, having as background the courses of Drawing, Technical Architecture, Materials Technology, Physics and Continuum Mechanics. The organizational method of the Theory and Design of Structures course is described below.

\section{Organization of the Course}

The course of Structural Engineering for the Bachelor students of Civil Engineering in Academic Year 2016-17 at the University of Cagliari is divided in two semesters:

- The theoretical aspects of the subject was explained in the first semester, using a mostly traditional kind of lecture

- The innovative part of the course took place during the second semester, which involved a didactic laboratory, addressed to the development of an individual structural design project of a building
The individual themes were assigned to a classroom of about 120 students. Each theme concerned a simple framed structure with comparable difficulty and it was generated from a common building with six identical frames. Simply removing beams or columns and changing the length, height, location of the structure and destination results in the final individual theme.

Figure 1 shown the plane frame used to generate the individual themes. Different span between columns and different heights were assigned together with various type of wind bracing.

A three dimensional frame is as reported in Fig. 2.

Some examples of individual themes generated by the plane frame are shown in Fig. 3.

Twelve groups of ten students received the same plane frame, with:

- Different measurements

- Different locations

- Different uses/destinations

Moreover the students were encouraged to adopt distinct structural materials (glued laminated timber, Steel, Reinforced concrete).

The individual themes were assigned at the end of the first semester. At the beginning of the second semester they were divided into four groups (about 30 students/group) each followed by a tutor. The students experienced the development of the project in classroom, in twelve sessions of three hours.

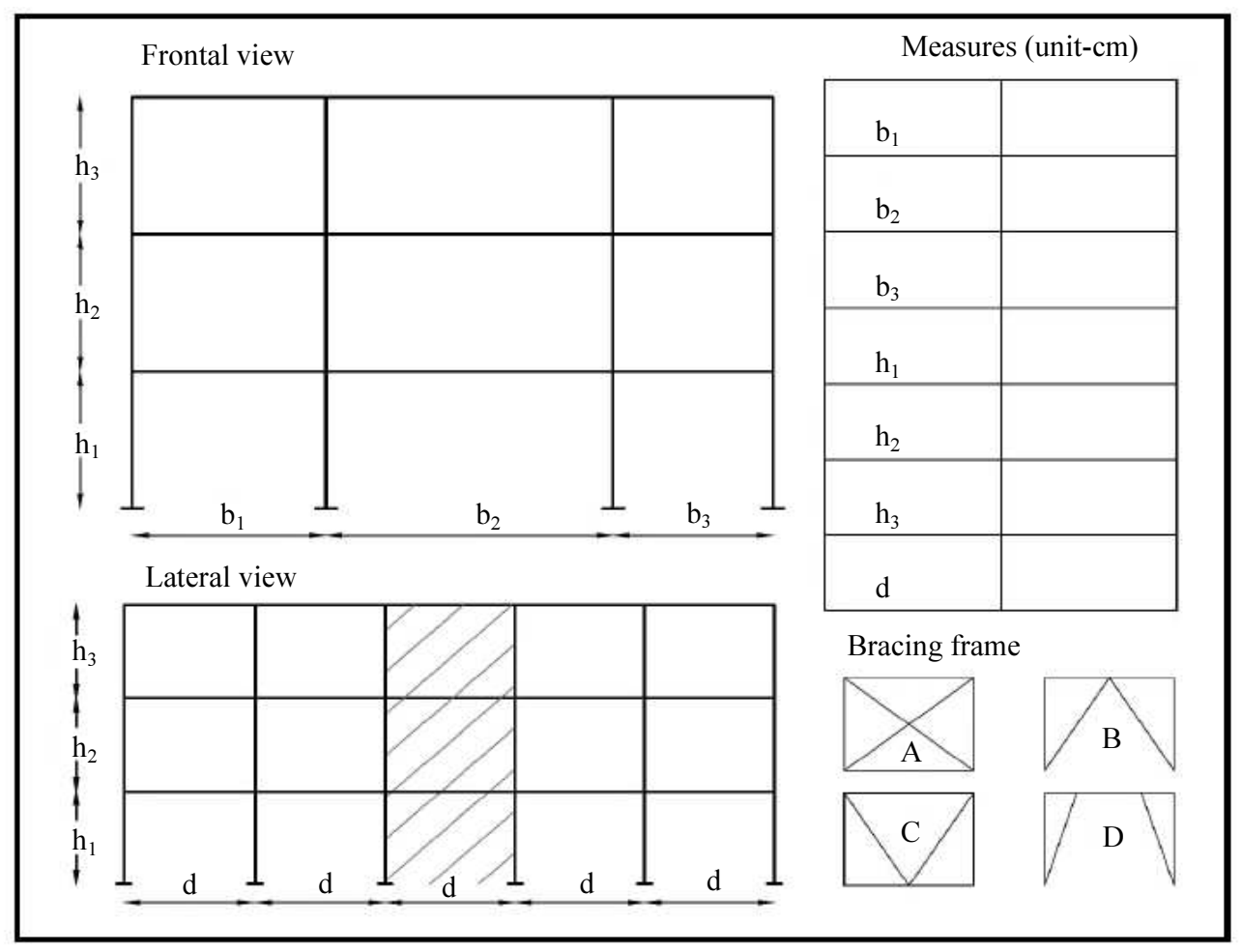

Fig. 1: Plane frame of the design project 


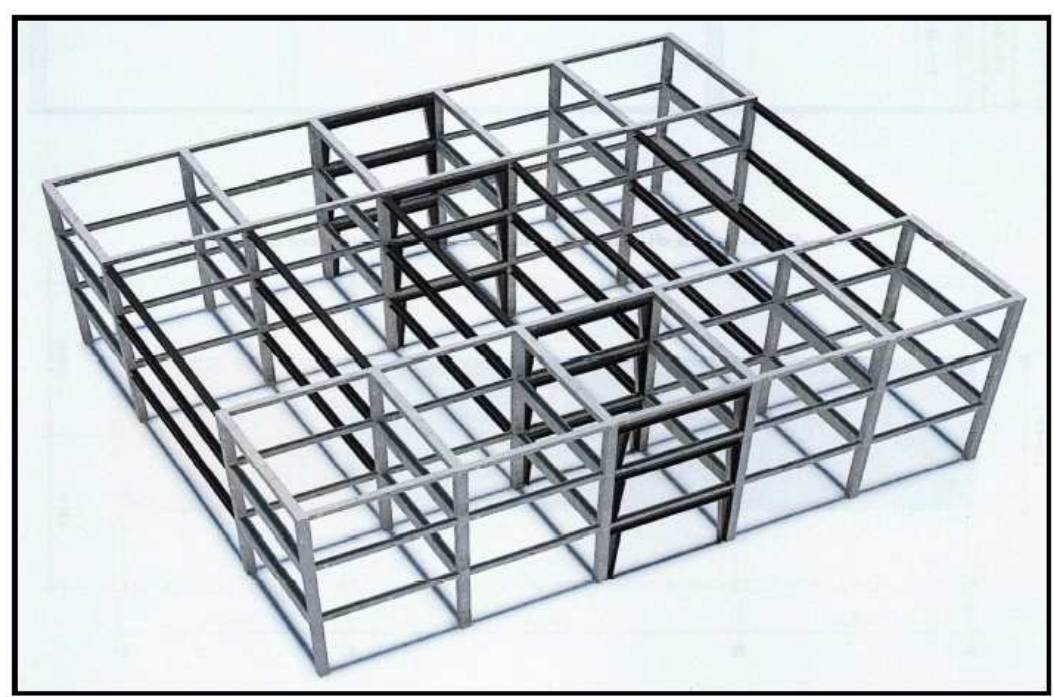

Fig. 2: Example of a student's three dimensional frame

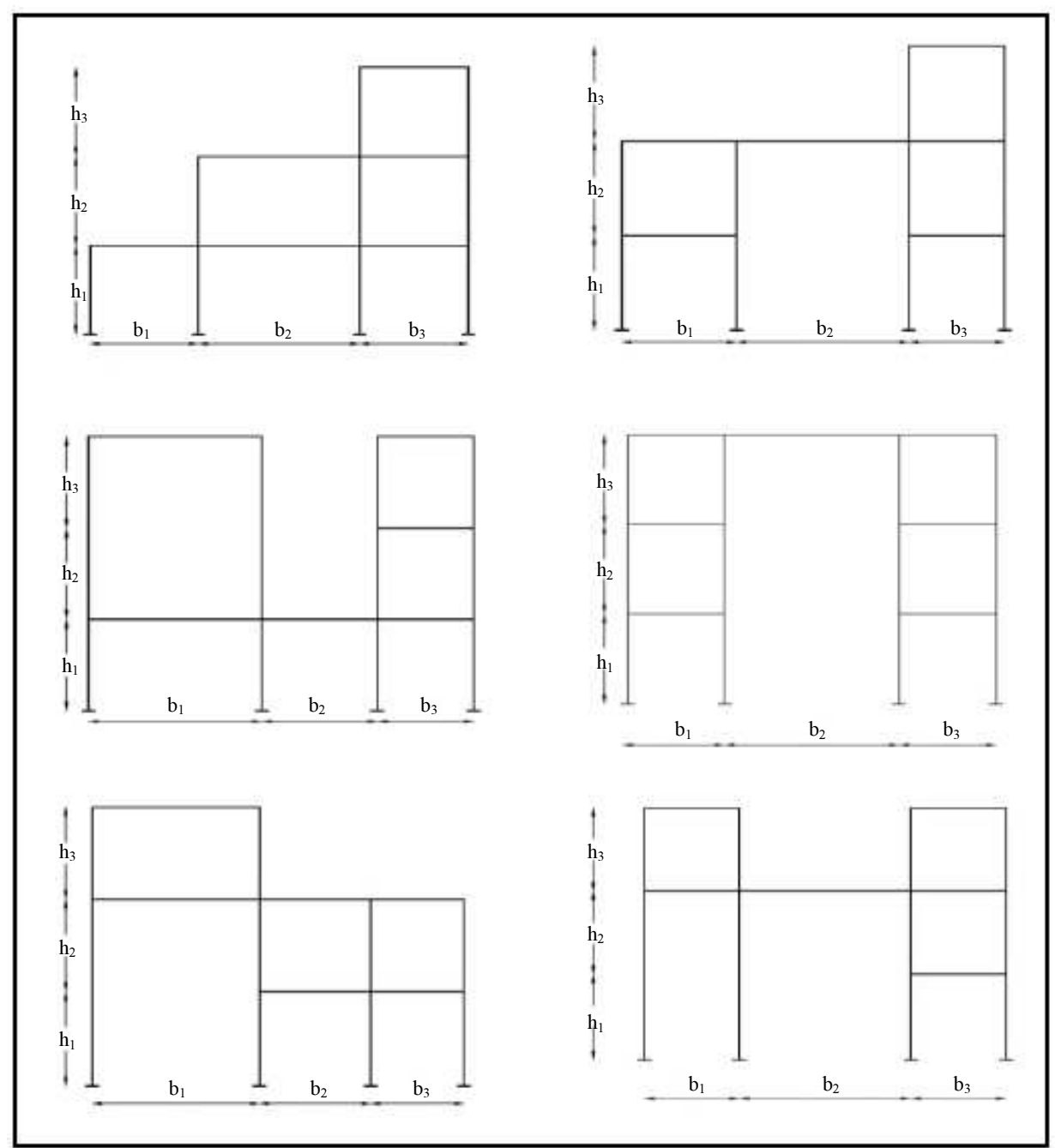

Fig. 3: Some individual themes of the structural design project 
Eight sessions were dedicated to develop a prescribed step of the project:

- In the first $1 / 2 \mathrm{~h}$ the teacher illustrated and assigned the activity to be done

- In the other $2,5 \mathrm{~h}$ the students developed the assigned activity with the help of the tutors

Two sessions were partially dedicated to verify the progress of the individual projects. Two more sessions were dedicated to harmonize the progress of the individual projects. In particular, the time table and the activities were the following:

- $\mathrm{n} .2$ plenary sessions to introduce all the activities to be done $(6 \mathrm{~h})$

- $\mathrm{n} .4$ sessions to develop the project (12 h)

- n.1 session to verify the project and to harmonize the project $(3 \mathrm{~h})$

- $\mathrm{n} .1$ session to harmonize the project $(3 \mathrm{~h})$

- n.4 sessions to develop the project (12 h)
- n.1 session to verify the project and to harmonize the project $(3 \mathrm{~h})$

- $\mathrm{n} .1$ session to harmonize the project $(3 \mathrm{~h})$

Individual forms were adopted for each student to report the individual activities. The form (Fig. 4) is organized in 3 parts:

- Main data - it contains the main info of the course (name, teacher academic year)

- Individual data - it contains the name of the student and of the tutor, the location and the destinati geometrical parameters to be considered and the table for the attendance record, completed by the tutor during each session

- Evaluation data - related to the laboratory first and to the final exam, late on of the building, the drawing scheme

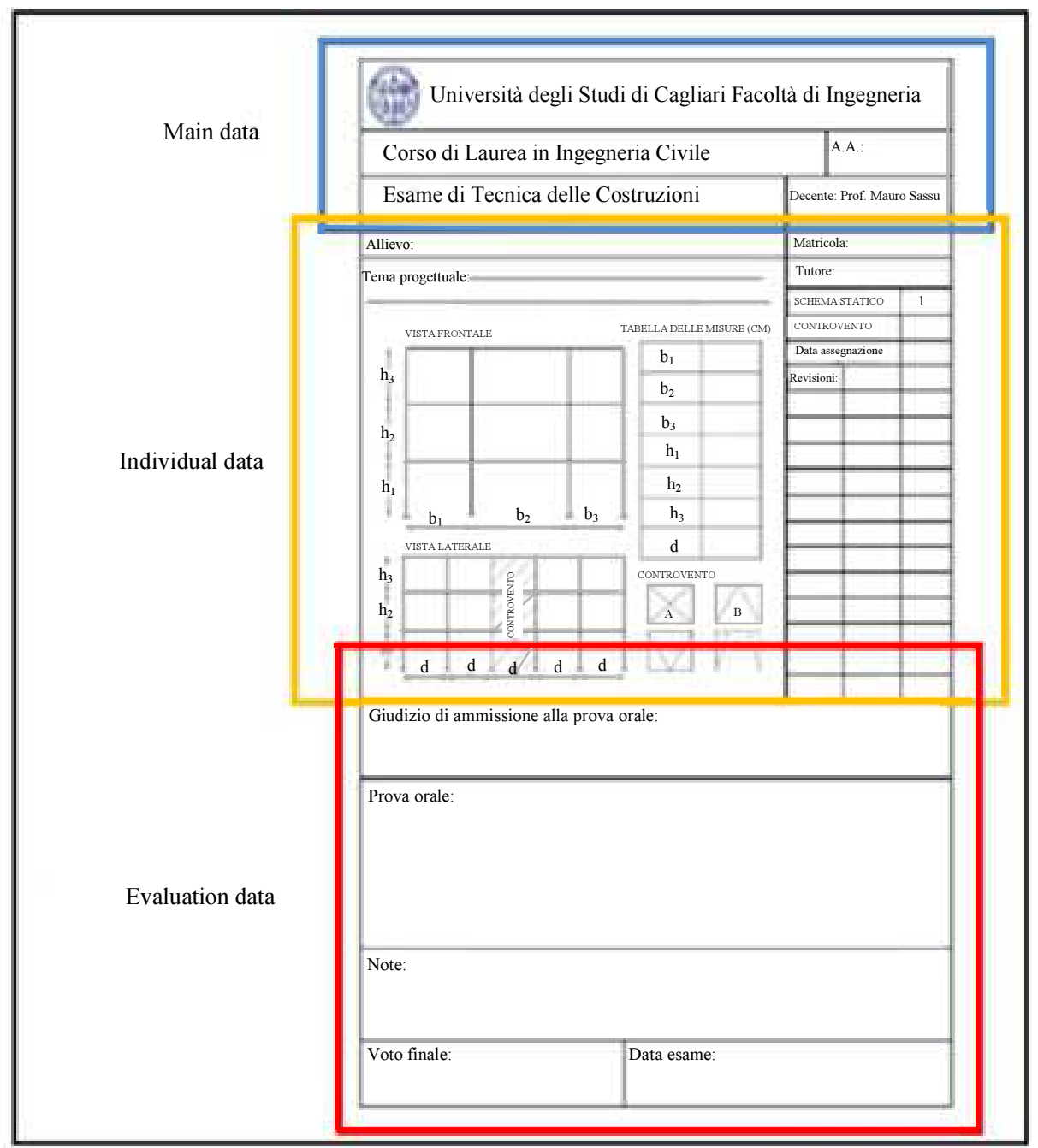

Fig. 4: Individual form for the project 
The evaluation was based on three parameters:

- Correctness of the choices, the calculations and the design of the structure

- Completeness of the report, of the calculations and of the drawings

- Clarity of the report, of the calculations and of the drawings

Finally, a "punctuality" parameter was assumed: The students were asked to respect a deadline, otherwise a reduction in the final mark was applied.

Letters grading system was used to evaluate projects:

- A (from $28 / 30$ up to $30 / 30$ )

- B (from $25 / 30$ up to $27 / 30$ )

- C (from $21 / 30$ up to $24 / 30$ )

- D (from $18 / 30$ up to $20 / 30$ )
The average mark results to be $\mathrm{B}+$ (about 26/30). More than $50 \%$ of students deliver the project on time. A further amount of about $15 \%$ of students deliver the project with acceptable delay. The large part of the remaining students decided to close the activities in the first month of the laboratory.

The students' attendance was monitored every week and registered within the form in Fig. 4. About the $60 \%$ of the students regularly attended the laboratory. The remaining students who did not complete the project has to repeat the laboratory in the following Academic Year.

\section{Development of the Project}

The work was organized following the various phases that characterize a real structural design project. Firstly, the load analysis was carried out: Dead loads, live loads as well as snow, wind and seismic actions have been considered (Fig. 5).
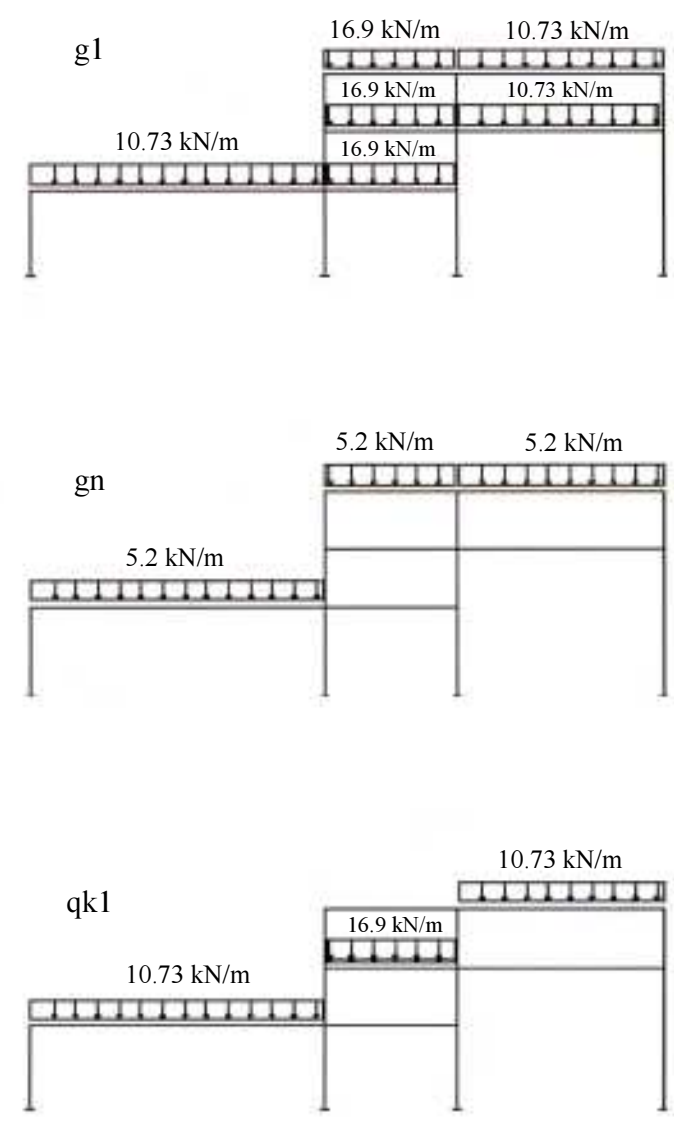


Fig. 5: Extract of a student's load analysis 


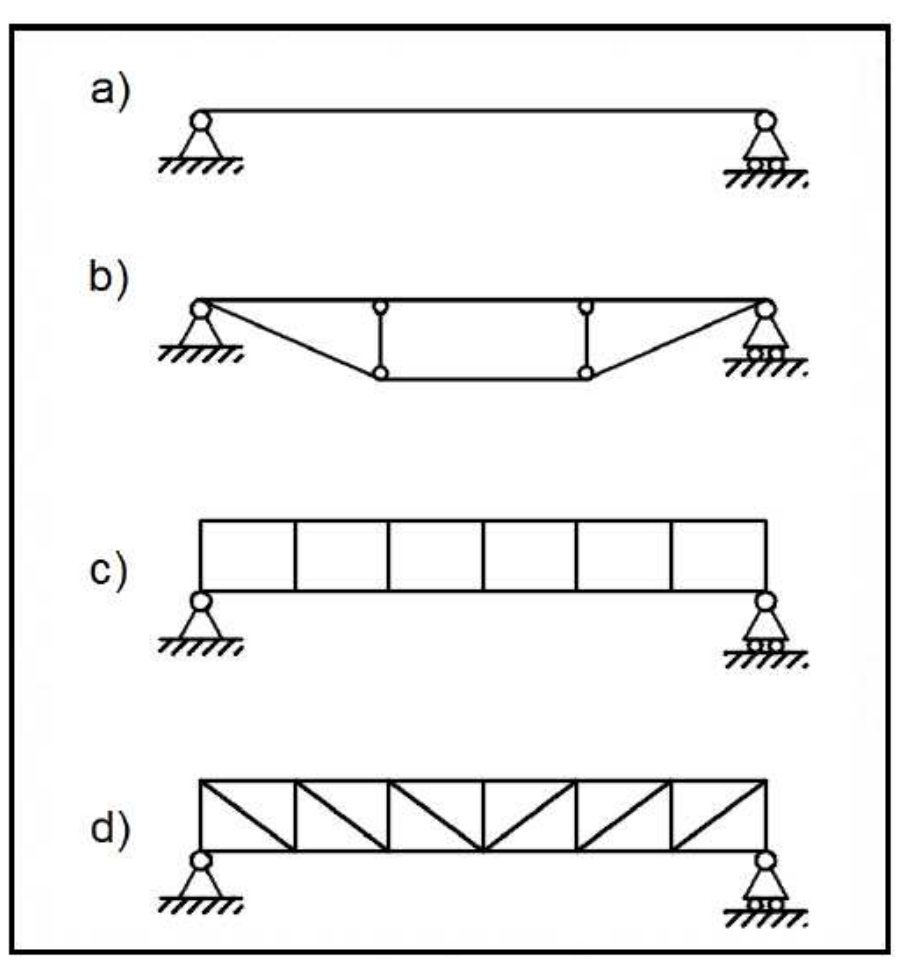

Fig. 6: Schemes of beams for design

The stress analysis has been performed separating vertical and horizontal loads. Static schemes of increasing difficulty have been identified: The purpose was to dimension the structure without using any automatic calculation tool. This choice is related to didactic purposes, since it stimulates the physical comprehension of the structural behaviour of each element of the structure. Finally, the seismic analysis was carried out using the simple "static-linear" calculation method: The students have in fact a lack of knowledge in Dynamics of the Structures. They are going to study this topic later in their master degree program.

The student was asked to choose within prismatic, stiffened, cellular or laced truss, as in Fig. 6.

All the components of the structure, including the bracing system, were assessed for both the ultimate (SLU) and the Serviceability (SLE) limit state.

\section{Results and Discussion}

Traditional teaching methods based on teachercentered classes and abstract concept, appear not be very stimulating even for students with strong passion and willing to learn. In order to overcome to this problem, the student was encouraged to actively participate to the activities proposed by the teacher. The main features we would like to point out about this new way to train engineers are:
- $\quad$ The student - tutor relationship

- The student - student relationship

- The approach to a real project for their first time

\section{The Student-Tutor Relationship}

According to a traditional method, the student simply sit passively, listening, coping from the board and possibly trying to avoid eye contact with professor. Commonly, he does not feel comfortable in asking questions to the teacher. In this sense, the tutor represents a mediator between the students and the teacher. He establishes an equal relationship with the students that results in a two-way conversation: The student is now capable to communicate its doubts and problems in a more profitable way (Fig. 7).

\section{The Student - Student Relationship}

Having individual themes forced students to work independently but at the same time encourage them to communicate and discuss among themselves. Getting information's from people with different backgrounds and point of view has been found to be very effective not only at increasing knowledge, but especially in developing a positive professional attitude. By working with others, the students acquire greater awareness of their own weaknesses and strengths as well as the possibility to compensate their own limitations (Fig. 8). 


\section{The Approach to a Real Project for the First Time}

The active participation to the laboratory appears to be a successful strategy, where students finally apply their knowledge to a real object. For the first time they deal with a real structural design, asking to respect time and space boundaries. By making them responsible for their own design decisions and errors, they are trained to become independent from the teacher and to relay only on themselves and on the colleagues' opinion, so that they will be prepared to overcome the real world challenges (Fig. 9).

\section{Future Improvement}

A possible way to improve punctuality is to provide students a lecture notebook dedicated to practical solutions. The teacher, together with the tutor, could create this tool in order to help students in solving all the issues they may encounter step by step during the developing of the project. Although, the lecture notes could prevent the student from improving organizational skills. In fact, if he follows too accurately the teacher guide lines he will not exercise his critical and creative thinking without learning from his own errors.

Also the use of an activities time schedule could be a proficient way to improve punctuality. The student has to make an effort in order to follow the schedule. On the other hand, this approach could be very time consuming because usually the student does not have enough experience to understand how long a specific activity is going to take.

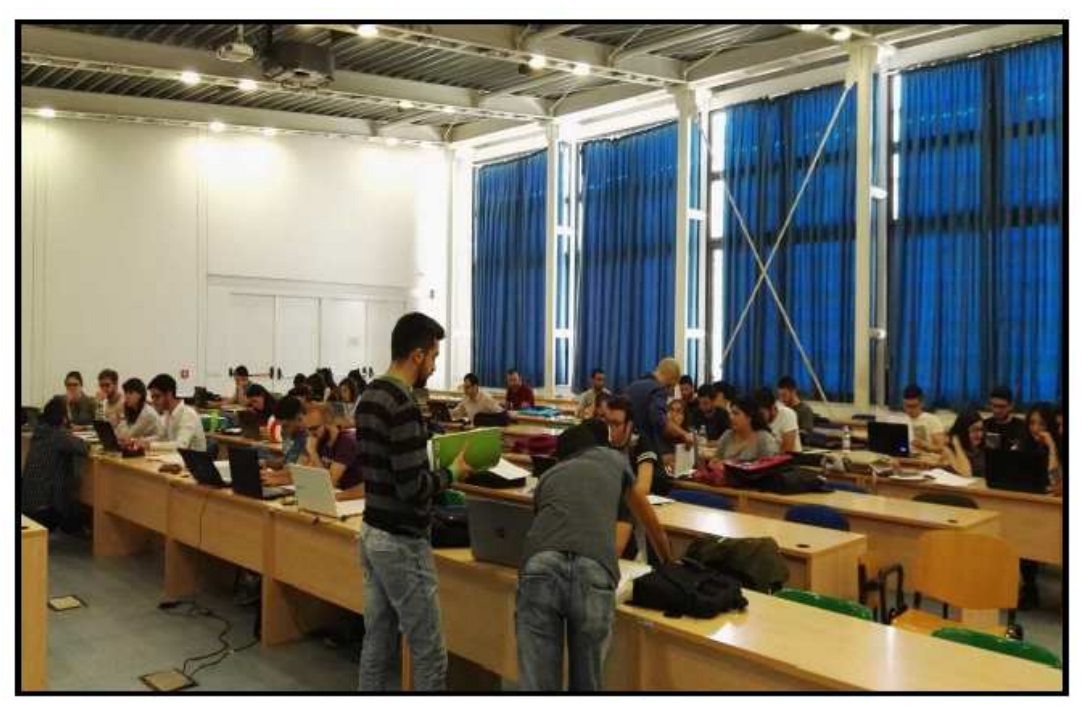

Fig. 7: The development of the project with the tutor's help

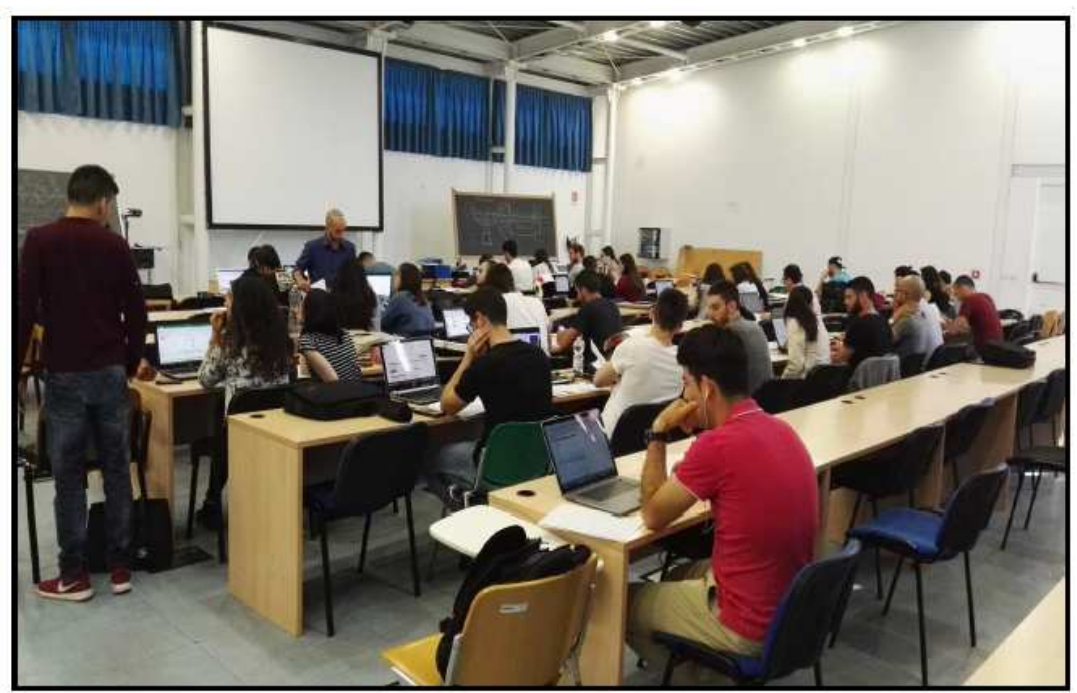

Fig. 8: The development of the project with the tutor's help 


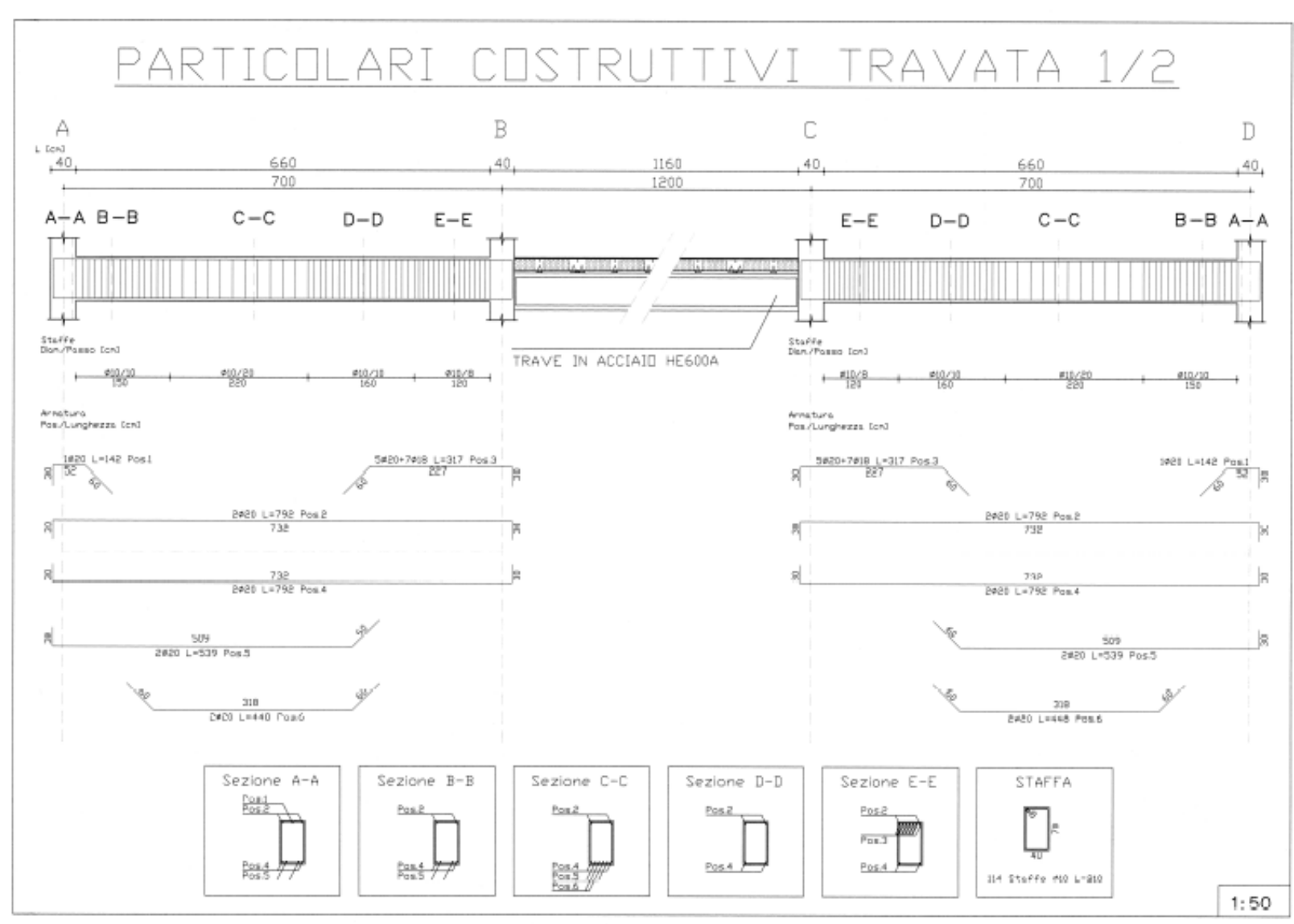

Fig. 9: Example of a student's technical design

The design skills of the students could be extended by reinforcing the use of FEM-based software of structural analysis.

\section{Conclusion}

The didactic laboratory on structural design implemented for about 120 students with the help of four tutors, during the 3rd year course on Civil Engineering at School of Engineering of the University of Cagliari, provided interesting indications. The major part of students reached the conclusion of their first structural design project on time with a profitable result. The content of the lectures could be improved together with an optimization of the tutor activities, in order to increase the average level of the design projects.

\section{Acknowledgement}

This paper was presented at the 6th International Workshop on Design in Civil and Environmental Engineering held at the University of Cagliari during November 9 - 10 - 11, 2017.

\section{Author's Contributions}

Mauro Sassu: Conceived the activities.

Mariangela Deligia and Fabrizio Pittau: Prepared the first draft of the article.

Silvia Corda and Michele Serra: Contributed referring their tutorage activity.

\section{Ethics}

All the authors declare the absence of any conflict of interests.

\section{References}

Breschi, A. and M. Sassu, 1997. Experimental teaching laboratory for in situ tests in historical churches. Proceedings of the 5th STREMAH, (STREMAH' 97), San Sebastian, Spain, pp: 129-138

Cropley, D.H. and A.J. Cropley, 1991. Creativity and innovation in systems engineering. Proceedings of the in Systems Engineering Test and Evaluation Conference: Conceiving, Producing and Guaranteeing Quality Systems, (GQS' 91), Systems Engineering Society of Australia, Adelaide, Australia. 
Liu, Z. and D.J. Schonwetter, 2004. Teaching creativity in engineering. Int. J. Eng. Edu. 20: 801-808.

Martin, J.C., 1991. Complete professionalism for engineers. Proceedings of the 21th Annual Conference on 'Engineering Education in a New World Order.' Frontiers in Education Conference, Sept. 21-24, IEEE Xplore Press, West Lafayette, IN, USA, USA, pp: 141-144. DOI: 10.1109/FIE.1991.187457

Rugarcia, A., R.M. Felder, D.R. Woods and J.E. Stice, 2000. The future of engineering education. Part I. A Vision for a New Century. Chem. Engr. Edu., 34: $16-25$.
Shaw, M.C., 2001. Engineering Problem Solving: A Classical Perspective. 1st Edn., Noyes Publications, Norwich, NY., ISBN-10: 0815514476, pp: 472.

Wu, J., M.X. Li, H.P. Xu and W.S. Chang, 2016. Learning by doing: A joint studio experiment on the theme of timber building design. Proceedings of the World Conference on Timber Engineering, Aug. 22-25, Wien, Austria. 